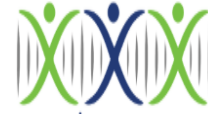

IRASD

Volume 9, Number 3, 2021, Pages 515-525

SCIENCES (PJHSS)

Journal Homepage:

https://journals.internationalrasd.org/index.php/pjhss

\title{
Investigating the Relationship between English Language Proficiency and Academic Performance of Engineering Students in Mehran University Jamshoro, Pakistan
}

\author{
Bibi Sadia Shah"1, Shumaila Memon², Habibullah Pathan ${ }^{3}$ \\ ${ }^{1}$ MS Scholar, Centre of English Language and Linguistics, Mehran University of Engineering \& Technology, Jamshoro, \\ Sindh, Pakistan. \\ Email: sadiashah54@gmail.com \\ ${ }^{2}$ Associate Professor, Centre of English Language and Linguistics, Mehran University of Engineering \& Technology, \\ Jamshoro, Sindh, Pakistan. \\ Email: shumaila.memon@faculty.muet.edu.pk \\ ${ }^{3}$ Director, Centre of English Language and Linguistics, Mehran university of Engineering \& technology, Jamshoro, \\ Sindh, Pakistan. \\ Email: dir.eldc@admin.muet.edu.pk
}

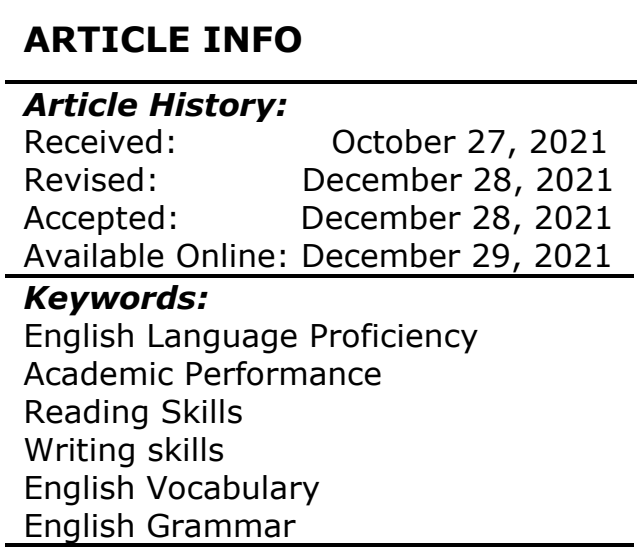

\begin{abstract}
The present study investigated the relationship between language proficiency and academic performance of students at Mehran university Jamshoro, Sindh. The study employed quantitative correlational research design to measure the variables. The researchers adapted English language test to measure the language proficiency of the learners and CGPA (cumulative grade point average) to measure the academic performance of the research participants. The researchers collected data from 100 undergraduate students by doing simple random sampling. The data was collected in two phases: first pilot study and then main study. The pilot study was done before the actual research to measure validity and feasibility of the adopted English language proficiency test. The Cronbach alpha was used to check reliability of the data. SPSS version 26 was used to perform the Pearson correlation analysis. The findings revealed that data was reliable with alpha value .702 and the correlation was highly positive with a value of .826 at the significance value .000 . The study confirms that the language has played a pivotal role to improve academic performance of the students studying in Mehran university of science and technology.
\end{abstract}

(c) 2021 The Authors, Published by iRASD. This is an Open Access Article under the Creative Common Attribution Non-Commercial 4.0

Corresponding Author's Email: sadiashah54@gmail.com

\section{Introduction}

Mehran University of Engineering and Technology enrolls students every year from every part of the country with varying degree of English language proficiency. This engineering university offers English language course in initial 2 semesters to equip students with English language. The current study examined the relationship between English (the language of instructions) and academic performance of learners at Mehran University of science and technology, Jamshoro.

English language, the language of progress and development, has long been dominated the political and official spheres of Pakistan like any other developing country on the globe. Increasing world-wide use of English language has added universalistic dimensions to the teaching and learning of English language in Pakistan.

The demands of Language expertise are extremely high in this age of globalization, especially in engineering field. Konar (2010) suggests in his study that, the requirements of this age have become even more complex and competitive for all whether it is students, professors, or professionals. For technical fields like engineering industry, communication skills are of 
profound importance. In this age of technology every field around the world is experiencing competition. In this struggle of existence, one needs updated knowledge and polished communication skills to justify their professional supremacy. Only those with required communication skills, can survive. Those with poor or less developed communication skills will lose out, and consequently, will get much less of what they deserve. Be it job opportunities, promotion or pay' (Monnipaly, 2008).

English language is world's current lingua franca. It is the language of communication around the globe which is extensively spoken and written language (Joshi, 2013). Engineering students who use English as second or foreign language they require good English skills for their academic achievements and career advancements. As Joshi (2013) further describes the significance of English skills of students doing engineering courses may face difficulty to make their career global if they fail to communicate efficiently in English. The main reason behind this value given to English language, is because English enjoys the status of present world lingua franca for international trade \& exchange, air travel and technology.

Communication skills have fundamental importance in engineering field. Regardless of how qualified and competent an engineer is, he/she needs to be competent enough in communication skills too. Thaky (2014) suggests that poor communications skills cannot help in uplifting engineering career for an engineer. As a professional engineer, one must deal with diverse types of clients with varying degree of fields, different academic backgrounds, and nationalities. If learners are unable to deliver their creative ideas and thoughts in its most appropriate way, it may leave negative impact on their engineering career. As Patil (2014) suggests in his study that, problem solving and analytical skills are crucial but in addition to these, subject-oriented knowledge, decision-making skills, research skills, management, understanding, confidently presenting their self, the ability to move with international clients and dealing with unfamiliar environment are the utmost important qualities for students seeking career in engineering field of study. The importance of English language for engineering students or engineering professional can be seen as important skill to excel in the field. The research question are given below;

RQ1: What is the relationship between language proficiency and academic performance of the students studying in engineering university?

RQ2: What is the difference between the English language proficiency of rural and urban background of students at MUET?

\section{Literature Review}

\subsection{Language Proficiency and Academic Performance}

One of the crucial parts of higher education is the proficiency in English language, considering English as the medium of instructions. English language proficiency or linguistic proficiency can be described as learners' ability to use English to speak or write in English language in meaningful manner (DEEWR, 2009). Furthermore, English language make students ready for comprehensive understanding of classroom instructions and better academic performance in the main subject areas of the study (Kong et al., 2012).

Educational success is generally referred as 'academic success' (Bahar, 2013a). University education in Pakistan uses English language as medium of instructions. Courses are taught in English, good language skills help in getting good marks in classroom setting, in such case, and English language proficiency has got important place in students learning experience. The understanding of English language contributes learners understating of overall subject matter and can enhance leaning quality at tertiary level of educations.

Academic scholars have long been working on the relationship between expert use of language and its positive influence on the student's end of the term result. The study by Wille (2006) has worked on the relationship between academic achievement and English language proficiency on secondary Hispanic students in US. The results of the study revealed considerably positive relationship exist between the variables. Another study carried by Sahragard et al. (2011) presented in Irani university examined the relationship between English language proficiency and academic performance of the students and to what extend proficiency can predict 
the positive outcomes of the learners. The participants' numbers for the study are 151 college students, doing bachelors in English literature. The results shown positively significant correlation exists between the variables. Another research study carried by Orgunsiji (2009) to know if there is any relationship of English expertise and their achievement in learning other subject matter success rate. They took 400 samples from 8 randomly selected secondary schools and the findings turned positive showing significant influence of language on academic scores of the learners of the school.

\subsection{Language Skills and its Influence on Academic Achievement}

Using a language require a whole lot of skills in transferring a thought into its concrete form be it spoken or written. Proficiency of language is a complete package of skills without which one cannot be called proficient in any language. There are several research studies to support language skills (speaking, writing, reading, and listening) and their connection to literary development. Stracher and Proffitt (2011) asserts the importance of quick decoding of words for language fluency. He added that reading a text and processing a text to be able to read, is a real struggle for many students. It signifies, the ability to decode the words while reading, is crucial for language fluency and comprehension to explain why leaners do not meet equivalence to their classmates who are considerably proficiency on their English reading comprehension abilities (Becker and Kim, 2014). For better and quick reading comprehension, word recognition and good vocabulary knowledge is required.

Whereas another study carried by O'Connor (2010) has revealed how reading comprehension in English language is linked with reading fluency in English. The findings confirmed that frequently struggling readers easily disengage their self from reading. Hence, complexes the existing reading ability. Cain and Oakhil (2011) maintained this point of view by stating that, good reading habit influences rich vocabulary development. The more student read in the language of instructions the more confident he/she will become in using that language. And will be able to present clearer and exceptionally well drafted ideas in the examination.

Some studies have shown zero to no influence of language proficiency on academic performance of the students' academic life. There are some research studies which show little or no significant relationship between the two. Aliakbari and Qsemi (2012) conducted a research study in Iran from 327 English language students shown low correlation between language proficiency and academic scores. Wongtrirat (2010) carried a meta-analysis research study on language and academic success relationship. The results shown considerably weak relationship of academic success, school leaving results or GPA, and entry level test (TOEFL) result of international students. Another research carried by Stevens, Butler and Castellon wellington (2000) concluded as no significant relationship between the variables, been found as the result of their study.

\subsection{Some Empirical Research Studies}

Educationalist have been working on the topic of language proficiency its relationship with the achievement of students. Some of the research studies are presented here to support my topic of research study. English language proficiency is the main skill which need attention from school level for developing competent youth, in this regard a cross-sectional study is carried by Kifayatullah in KPK Pakistan.

Kifayatullah (2019) conducted a cross-sectional quantitative research study for comparing the perception of learners and teachers about the relationship between language proficiency and educational performance at secondary level literacy in Khyber Pakhtunkhwa Pakistan. For data collection process 1975 students' responses and 108 teacher's responses were recorded for analyses from seven divisions of Khyber Pakhtunkhwa Pakistan. Questionnaire used close ended questionnaire the reason for choosing this type of research instrument was because it is much easier and comparatively less time consuming for analyses process. For the research instrument validity and reliability, the instrument is reviewed by experienced PhD intellectuals and English language lecturers of the main field of study. They acknowledged the instrument as clear, easy to use, and valid for the study through their analyses. Cronbach alpha was used for data reliability. The data declared reliable by achieving the Cronbach alpha value greater than .702 Independent sample t-test was utilized to analyze and differentiate the perception of teachers and students about the language abilities of their secondary level school students. The 
analysis of the study revealed that students do lack complete language proficiency of English, but they do have command over few skills of English language.

The research work in Pakistani context is carried by Kamaluddin and Mohammad Saeed (2018). The topic of research carried, was the correlation between the proficiency of Pakistani students and their academic success scores. The research study used mixed research methodology. They took 600 samples of undergraduate students from social sciences and human resource management from two Pakistani public sector universities by using purposive sampling technique. Self-made questionnaire with 26 items was developed as a data collecting tool for the research. Cronbach alpha value .80 achieved by doing pilot study of 50 samples which indicated good reliability. The result of one English subject and one general subject currently from enrolled students were used. The results of the study shown a moderate but significantly correlation between the variables of the study (language proficiency and academic achievement) with the Pearson correlation value .488. English language competency and academic success had slightly negative but statistically considerable relation with satisfaction $(p<0.05)$. Also, regression analysis discovered English language proficiency variability of $23 \%$ in academic success.

\section{Research Design}

The researcher has chosen quantitative research methodology and correlational research method to investigate the relationship between the first variable, (language proficiency) and second variable (academic performance). Correlational research type is the type of method which is based on the sound conceptual/theoretical framework of the study. The primarily goal of this research methodology is to establish a relationship between two or more type of variables by collecting data for those research variables and doing correlation coefficient between them (Gall, Gall, \& Borg, 2007). In the current research study two variables are used, first is (independent) English language proficiency and second is (dependent) CGPA of the students studying in Mehran University Jamshoro. The second question of the study examines the difference found between languages proficiency of students who are belong to urban background and those who belong to rural background. The data for second question is collected through demographic form and analysis is taken place by independent T-test.

The correlational research is the good choice to present empirically the relationship between English language proficiency and academic performance in regards to how closely these variables are related (McMillian, 2006). CGPA is used for the academic performance of students and English language proficiency skills (grammar, reading, writing and vocabulary) are achieved by the help of English language test adapted from ESOL Cambridge for engineering students studying in Mehran University Jamshoro. The sample size is 100 participants, which is chosen according to the studied literature review of previous studies. Among types of correlations, the current researcher has used Pearson correlation research design to investigate the co-existence of the relationship between students CGPA scores (criterion variable) and English language proficiency (predictor variable), while moderating the influences of gender, age, intermediate and matriculation study background, and grade levels achieved. 3 variables of the study reading grammar and vocabulary are analyzed through answer keys provided by the test website. Whereas for the writing tasks, the researcher has used Analytic Rubric of Angel and Garcia (2019) to grade the students' essays. The essays were mainly assessed on 5 levels of writing assessment framework given by Angel and Garcia namely, (i) Discourse; (ii) Organization; (iii) Syntax/Structure; (iv) Conventions; (v) Vocabulary.

\subsection{Population and Sampling}

A research population has been defined as a group of participants, objects, or institutes which carry considerably similar qualities or characteristics, similar disciplines, values, and gender. In research and education, the term sample represents a collection of individuals or items who are selected from a larger population for measurement research purpose. For this study random sampling was used out of many types of sampling. Random sampling is described as a sampling method which prioritizes random selection of participants from the sample. It means, every participant or sample from the larger population has got equal chance of selection for the study. And selected sample represents the population to generalize the results research study. The researcher conducted test from 100 participants from 3 departments of Mehran 
University of science and technology. These participants were given 50 minutes to complete the English grammar, reading comprehension, writing and vocabulary test.

\subsection{Research Instruments}

The current research study presents the correlational research type where one variable is correlated to other, to check if there is any correlation between them. In this regard English language proficiency of students studying in engineering university, has examined by the researcher. To know the proficiency levels of the learners, the researcher adapted English language test by the help of CEFR common English language framework for reference. CEFR is a language testing framework developed to elaborate language learning material, syllabus curriculum and tests on a common, standardized base, defines the context of language learning, the skills needed to perform language in a communicative way, as well as to introduce levels of language proficiency by which learners' language skills and progress can be measured (Council of Europe, 2001). It was mainly developed as a framework for language learners, teachers, and educational administrators of Europe but today it is regarded as one of the valid and reliable language testing frameworks that is used worldwide.

The language testing Framework CEFR is comprised of six different levels of language proficiency, starting from very basic or beginner level (A1) to the highly advanced level (C2). This framework is available in 39 different types of languages online, and it comprehensively describes the tasks and activities a learners can do at each of these levels of language proficiency. It primarily focuses on the linguistic skills namely reading, writing, listening, and speaking. It not confined to any one language rather it works on general framework of languages which can be applied to any language across the European Union. CEFR framework is also used for the leaning practices of languages in other part of the globe, from Japan to China it is considered as helpful tool to create content for language learning and organizing the language classes.

CEFR framework works in the most organized way, at the A2 level a learner can make understanding of simple and short texts with simplest and most used words. A2 writing tasks also include simple writing, simpler precise notes of everyday life conversation. Whereas at B2 level learner can be able to read different kinds of texts with good speed understanding. At B2 level learner can write essays, can extract required information from the text and write in their own wordings and language. CEFR framework is serving its role to the teachers, textbook content creators, and language assessors and exam makers (Cambridge English exam). It ensures them they are working on right content according to learners' levels. Using this framework make them sure that their content just right. Not too easy or too difficult to solve.

Following the figure 1, language test was adapted for the research which comprised of four skills of English language, namely Grammar, Reading, Writing and Vocabulary. The grammar test comprises of 15 mcqs, reading test consists of 2 tasks having 6 items in first task and 9 items in another task, writing test has 2 sections: 1. Picture description. 2. Essay writing, and vocabulary test that included 15 mcqs. Individual score of each test was calculated and given in the form of numbers, mean, standard deviation, and range.

Figure 1

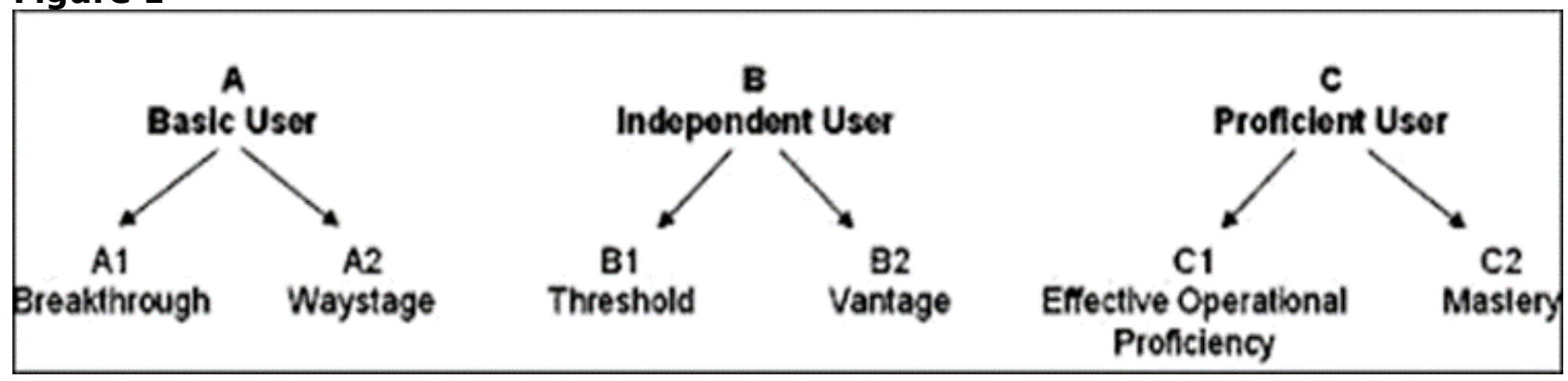

Figure Presentation of common Reference levels (councils of Europe, 2001)

\subsection{Demographic Information Form}

Demographic information form was adapted by the researcher to collect information of respondents regarding their academic performance, in the form of percentage or CGPA they achieved. The analysis of academic performance of students was based on CGPA score of respondents. 
Table 1: English language test instrument used in present study is given below

\begin{tabular}{ccc}
\hline Types of Variables & $\begin{array}{c}\text { Number of Items from each } \\
\text { Level of Proficiency }\end{array}$ & $\begin{array}{c}\text { Total Items from each } \\
\text { Variable }\end{array}$ \\
\hline Grammar & 5 Items from KET & 15 \\
15 marks & 5 Items from PET & \\
Reading & 5 Items from FCE \\
15 marks & Task 1 from PET & 2 \\
Writing & Task 2 from FCE \\
25 marks & Task 1 from PET & 2 \\
Vocabulary & Task 2 from FCE & \\
15 marks & 5 Items from KET & 15 \\
\hline
\end{tabular}

\subsection{Data Collection Procedures}

Data is collected into two phases, first pilot study of 10 respondents and then main study of 100 respondents of the actual data of the study. Pilot study in social sciences, is used into two different ways. It can be used as feasibility studies which are small research version of the main study or trial run done for the preparation of the main actual research study (Polit et at., 2001). Pilot study confirmed the feasibility of the research protocol and validity and reliability of the research instrument. After pilot study the researcher was able to estimate exact time taken by each participant to complete the test that greatly helped in the carrying out the main research study of larger population of 100 participants.

For the main study, 120 tests papers were distributed into three 3 different departments of Mehran university namely: Industrial engineering, Chemical engineering, and Bio medical engineering. Out of which 100 respondents were collected and used for the data analysis process.

\section{Results and Discussion}

\subsection{Reliability of the Data}

Reliability is the consistency of scores in a test. It describes how much the data is reliable and consistent. This section will elaborate the reliability of the tests and scores applied in the research and through SPSS Software. The table 2 shows the reliability of the overall tests applied in the research. The value of Cronbach's Alpha is indicating that items which were included in the questionnaire are internally correlated data and reliability of the data is good for this research. In the fields of social sciences, Cronbach alpha value or reliability value of .6 is considered acceptable for the research study. Whereas the current study has .704 Cronbach alpha value which is remarkably good and shows that, the items used in the construct of research instrument are reliable to carry the research. Total number of items is 45 (15 grammar, 15 vocabulary, and reading 15.

Table 2: Reliability Statistics

\section{Cronbach's Alpha} No of item

\subsection{4} 40

Figure 2: Frequency, means and standard deviation of CGPA of the respondents

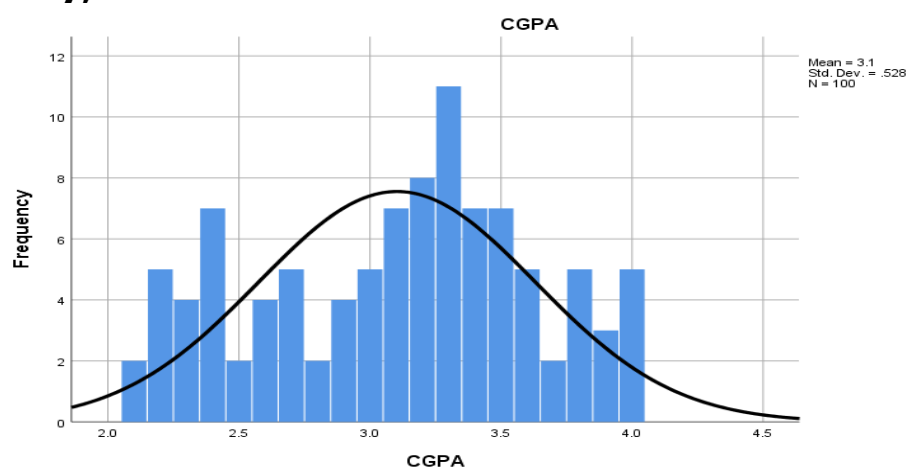


Figure 2 shows the flow of the CGPA as mentioned by the participants of this study by their self. The above graphs show the respondents of this study are mostly having their CGPA between 3.0 and 3.5. The flow of the CGPA achieved as academic success of the students goes till 4 CGPA. Figure 3 shows maximum number of students achieved language proficiency test score between 50-60 scores out of total 70 marks. With the mean $=47.76$ and standard deviation 8.685 .

Figure 3: Frequency, means, and standard deviation of Total-Test-Marks-Obtained by the respondents

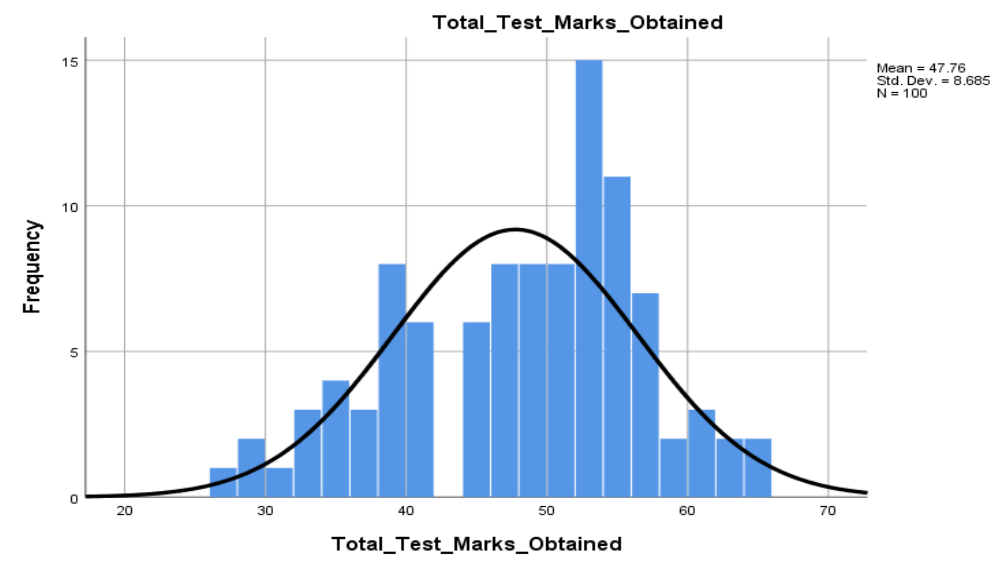

Table 3 shows the result of Correlation which is the main study defining correlation between total marks obtained by the participants of this study and CGPA score of the participants. The results of this correlation are highly positive correlation with the values .826, correlation is strongly correlated if the score comes near to value 1 . And is significance score .000 shows that relationship is also considerably good. This confirms that language proficiency has positive and significant correlation academic performance of the students studying in engineering university. Four more correlation were carried to describe which skill has stronger influence on academic performance being measured by CGPA as compared to others.

Table 4 shows the correlation between CGPA as academic performance of the students and its relationship with the writing marks obtained by the participants of the study. The correlation between these variables is the second highest positive correlation found after first main study correlation (correlation no.01). The value obtained is the .790 and with highly significance value of .000 . It confirms English language writing marks has great influence on overall achievement of students studying in engineering university. Students who have command over good writing skills have added benefit, and this skill is important as compared to other language skills.

Table 3: Correlations 1

\begin{tabular}{llcc}
\hline & & Total-Test-Marks-Obtained & CGPA \\
\hline Total-Test-Marks- & Pearson Correlation & 1 & $.826^{* *}$ \\
Obtained & Sig. (2-tailed) & & .000 \\
& $\mathbf{N}$ & 100 & 100 \\
CGPA & Pearson Correlation & $.826^{* *}$ & 1 \\
& Sig. (2-tailed) & .000 & 100 \\
\hline
\end{tabular}

** Correlation is significant at the 0.01 level (2-tailed)

Table 4: Correlations 2

\begin{tabular}{cccc}
\hline & & CGPA & Writing marks \\
\hline CGPA & Pearson Correlation & 1 & $.790^{* *}$ \\
& Sig. (2-tailed) & & .000 \\
$\mathbf{N}$ & $\mathbf{N}$ & 100 & 100 \\
Writing marks & Pearson Correlation & $.790^{* *}$ & 1 \\
& Sig. (2-tailed) & .000 & 100 \\
\hline
\end{tabular}

**Correlation is significant at the 0.01 level (2-tailed) 
Correlation given in table 5 shows the correlation between CGPA score and grammar marks obtained by the participants of the study. This also shows moderate but positive correlation between the academic performance and Grammar marks of the students.

Table 5: Correlations 3

\begin{tabular}{cccc}
\hline & & CGPA & Grammar Marks Obtained \\
\hline CGPA & Pearson Correlation & 1 & $.508^{* *}$ \\
& Sig. (2-tailed) & & .000 \\
$\mathbf{N}$ & 100 & 100 \\
Grammar Marks & Pearson Correlation & $.508^{* *}$ & 1 \\
Obtained & Sig. (2-tailed) & .000 & 100 \\
& $\mathbf{N}$ & 100 & \\
\hline
\end{tabular}

**Correlation is significant at the 0.01 level (2-tailed)

Correlation given in table 6 is another correlation between CGPA and vocabulary marks which are obtained by the students and it shows moderately good correlation score between the variable. It describes the importance of vocabulary and how it helps in getting CGPA score for the engineering students at Mehran University.

Table 6: Correlations 4

\begin{tabular}{cccc}
\hline & & CGPA & Vocabulary Marks \\
\hline CGPA & Pearson Correlation & 1 & $.491^{* *}$ \\
& Sig. (2-tailed) & & .000 \\
& $\mathbf{N}$ & 100 & 100 \\
Vocabulary Marks & Pearson Correlation & $.491^{* *}$ & 1 \\
& Sig. (2-tailed) & .000 & 100 \\
\hline
\end{tabular}

** Correlation is significant at the 0.01 level (2-tailed)

Table 7: Correlations 5

\begin{tabular}{cccc}
\hline & & CGPA & Reading Marks Obtained \\
\hline CGPA & $\begin{array}{c}\text { Pearson Correlation } \\
\text { Sig. (2-tailed) }\end{array}$ & 1 & $.474^{* *}$ \\
& $\mathbf{N}$ & 100 & .000 \\
Reading & Pearson Correlation & $.474^{* *}$ & 100 \\
Marks & Sig. (2-tailed) & .000 & 1 \\
Obtained & $\mathbf{N}$ & 100 & 100 \\
\hline$* *$ Correlation is significant at the 0.01 level (2-tailed) & &
\end{tabular}

Correlation given in table 7 is correlation between CGPA and reading marks which are obtained by the respondents and it shows moderately high and significant score. Before doing the correlations, I made sure that the variables have normal distribution and are continuous. All the five Correlations (CGPA- total marks, CGPA-reading CGPA-writing CGPA-vocabulary, CGPAGrammar) have a positive Pearson Correlation coefficient. In other words, students with higher levels of CGPA has been scored higher at proficiency levels and their relationship is positively high. And the significance level is also well below 0.01 which means this result is statistically significant.

The study confirms that having good command over English language helps getting good academic CGPA, even in the field of engineering. Correlation no 01 is the main study correlation other 4 correlation tables $(03,4,5,6)$ shows the relationship between individual skills with the grade point average of the students. The other correlations between individual skills shows how closely each skill is responsible for the influence on overall academic performance of the student's end of the year assessment score. That is showing the results of the RQ1.

For the analysis of RQ2, the researcher has gathered data from same 100 sample size, by the help of demographic form. Below is given the description of frequency and percentage of rural and urban background students studying in Mehran University. Table 8 shows the percentage and frequency of participants with respect to their areas where their domicile belongs to. This information is crucial in determining the background of the students studying in Mehran 
university of Jamshoro. This information is given in the demographic form presented to each participant before the test. It includes that $45.1 \%$ respondents belong to Urban, and 52.9 respondents belongs to rural background.

\begin{tabular}{ccc} 
Table 8: Frequency and Percentage Urban and Rural the Respondents \\
\hline Domicile & Frequency & Percentage \\
\hline Urban & 46 & 45.1 \\
Rural & 54 & 52.9 \\
Total & 100 & 98.0 \\
\hline
\end{tabular}

Figure 4: Bar Charts Showing Percentage of Urban and Rural Respondents

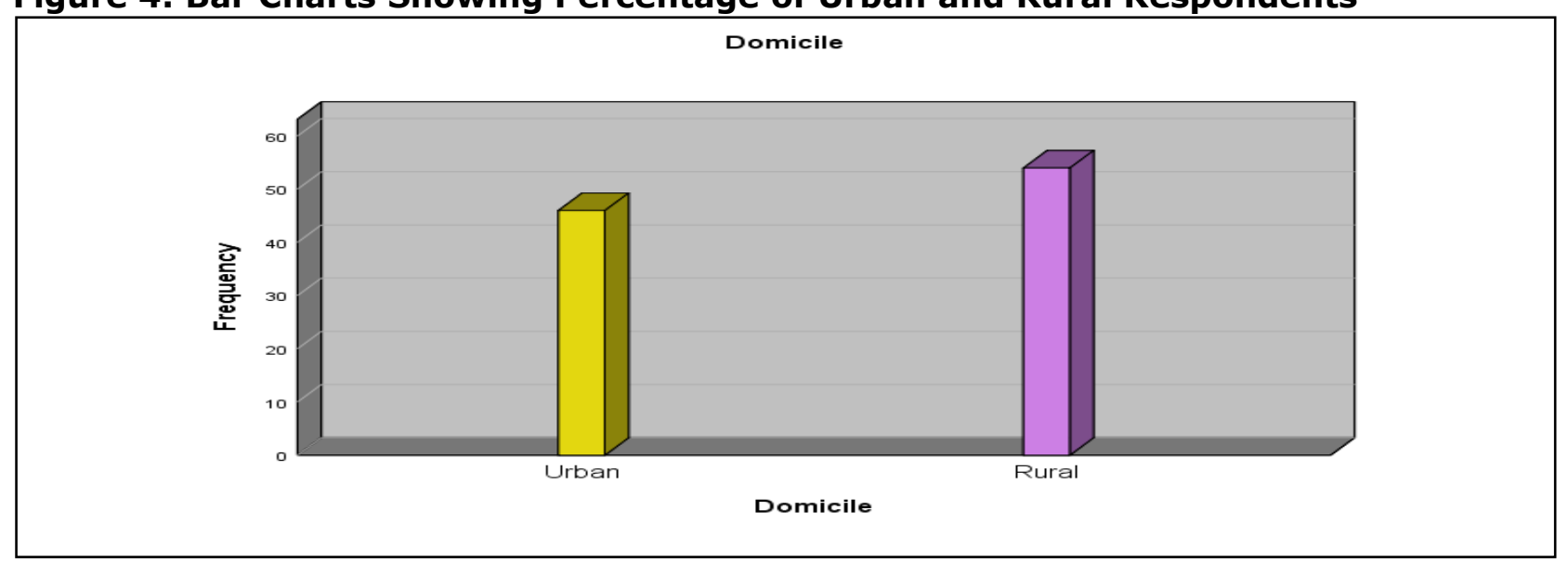

Figure 4 shows the Bar chart and it shows the frequency of urban and rural students

Table 9

\begin{tabular}{lcccc}
\hline & Domicile & N & Mean & Std. Deviation \\
\hline \multirow{2}{*}{ Total Test Marks Obtained } & Urban & 46 & 48.83 & 8.236 \\
& Rural & 54 & 46.85 & 9.027 \\
\hline
\end{tabular}

Group statistics is showing that how domicile (urban and rural) is distributed among students. $46 \%$ students belong to urban areas of the country and $54 \%$ students belong to rural areas of the country (Pakistan). Urban domicile is having mean 48.83 and standard deviation 8.236 whereas, rural is having 46.85 group mean and 9.027 standard deviation.

Table 10

\begin{tabular}{ccc}
\hline t Statistics & df & Sig. (2-tailed) \\
\hline 1.135 & 98 & 0.259 \\
\hline
\end{tabular}

Independent t-test analysis table for RQ2.

As significance level is greater than 0.05 so the result is not statistically significant, and we cannot reject the null hypothesis (the difference in group means is zero). Df (degrees of freedom as 98 and t score 1.135 (which means the first group's mean is slightly greater than second group(rural) but as significance level is not below the $5 \%$ level so we cannot apply it.

\section{Disscussion}

The results of RQ1 are consistent with Parker et al. (2009) study that English language proficiency helps in getting success in numerical subjects. So, the improvement in English language skills of students can help in getting better understanding of mathematics subject assessment for those students, whose first language is other than English (Essien \& Setati, 2007). Another research by Nasirudeen and Song Xiao (2020) on Asian domestic and international nursing students of Singapore investigated how language proficiency influences positive outcomes of the students. The finding shows there is considerable impact of language proficiency on international students. The current study reveals that improving English language skills of students can help in improving the overall academic performance of students studying in engineering courses. All four of language areas (grammar, reading, writing and vocabulary) has yield positive relationship between the learner's academic scores. Whereas each skills 
individual correlation has also shown positive relationship but, writing skill has the strongest influence or correlation coefficient value with CGPA. As long as RQ2 is concerned, independent t-test carried between the groups has not yield any positive or significant relationship. That means, in the case of current study, urban or rural background of the students has little or no influence over learner's English language skills/proficiency.

\section{Conclusion}

English language, the language of success and opportunities, has always been admired for the access of higher education and prosperity. Almost all fields of human life are getting benefit of information and technology by the help of their good command over English language. Proficiency in world power-language (English) and success in academic and professional life has strong relationship. Academic researchers have paid great attention to many possible determinants of student's performance. They have tried to look for the variables which are responsible for negative or positive impact of a student's performance and language plays vital role in this regard (Haydar \& Uyar 2011).

The study investigated the language proficiency by adapted English test and academic performance by CGPA acquired by the students, considering technical courses have more numerical type and less comprehensive courses as compared to social sciences field of study. The study implies in highlighting the importance of learning English for academic achievement at engineering university. It inculcates various plans and development programs for forging English language proficiency. It paves the ways for the ELT practitioners for research in these areas of study. In ESL/ EFL context including Pakistan where English language plays an indispensable role, in education, business, media and government, the officials need to design the books that have the material to get grip on general English language skills. Which include must include, academic writing, reading, grammar and vocabulary areas of language. And teachers are needed to follow the suitable teaching methodologies and adapt or adopt the authentic material from the reliable sources to strengthen the language skills needed for the successful attempt of learning assessment.

\section{References}

A.M.A. Nasirudeen 1 \& Song Xiao (2020). English Language Skills and Academic Performance: A Comparison between Asian International and Domestic Nursing Students in Singapore.

Aliakbari, M., \& Qsemi, N. (2012). On the relationship between Iranian EFL learners' learning style preference and their gender, proficiency level and achievement score. International Journal of Pedagogies and Learning, 7(3), 275-283.

Cain, K., \& Oakhill, J. (2011). Matthew effects in young readers: Reading comprehension and reading experience aid vocabulary development. Journal Learning Disabilities, 44(5), 431-443.

Cummins, J. (1976). The influence of bilingualism on cognitive growth: A synthesis of research findings and explanatory hypotheses. Working Papers on Bilingualism, 9, 1-43.

DEEWR, (2009). Belonging, being \& becoming: The early years learning framework for Australia. Canberra: Commonwealth of Australia.

Din, K. U., \& Saeed, M. (2018). Relationship between University Students' English Proficiency, academic achievement and their satisfaction on teacher feedback. Bulletin of Education and Research, 40(3), 129-143.

Essien, A. A., \& Setati, M. (2007). Exploring the English proficiency-mathematical proficiency relationship in learners: An investigation using instructional English computer software. In J. H. Woo, H. C. Lew, K. S. Park, \& D. Y. Seo (Eds.). Proceedings of the 31st Conference of the International Group for the Psychology of Mathematics Education, 2, 217-224.

Gall, G., Gall, J., \& Borg, W. (2007). Education research: An introduction (8th ed.). Boston, MA: Pearson Education, Inc.

Haydar, A. \& Uyar, A. (2011). Factors Associated with Student Performance in Financial Accounting Course. European Journal of Economic \& Political Studies, 4 (2), 139-154.

Joshi DH (2013), Importance of English Language for the Student of Engineering. International Journal of Technical \& Non-technical Research, 4(3), 50-54.

Khan, K., \& Khan, W. (2020). Perceptions of Students and Teachers about Students' Proficiency in English Language at Higher Secondary Level in Khyber Pakhtunkhwa, Pakistan. International Journal of English Linguistics, 10(1), 15-25.

Konar N (2010), Communication Skills for Professionals. PHI Learning Private Limited, New Delhi. 
Monippally MM (2008), Effective Technical Communication. The McGraw Hill Companies, Delhi.

O'Connor, R. E., Swanson, H. L., \& Geraghty, C. (2010). Improvement in reading rate under independent and difficult text levels: Influences on word and comprehension skills. Journal of Educational Psychology, 102(1), 1-19.

Orgunsiji, Y. \& O, F. D. (2009). English Language Proficiency as a predictor of Academic Achievement among EFL students in Nigeria. European Journal of Scientific Research, 37(3), 490-495.

Parker, C. E., Louie, J., \& O'Dwyer, L. (2009). New Measures of English Language Proficiency and Their Relationship to Performance on Large-Scale Content Assessments. Issues \& Answers. REL 2009-No. 066. Regional Educational Laboratory Northeast \& Islands. Retrieved from http://ies.ed.gov/ncee/edlabs.

Patil, M. R. (2014). Importance of English communication for engineering students from rural areas and its remedies. IOSR Journal of Mechanical and Civil Engineering (IOSRJMCE), 35-38.

Sahragard, R. Baharloo, A. \& Soozandehfar, S. M. A. (2011). A closer look at the relationship between academic achievement and language proficiency among Iranian EFL students. Theory and Practice in Language Studies, 1(12), 1740-1748.

Shrestha, R. N., Pahari, B. R., \& Awasthi, J. R. (2015). Impact of English on the career of engineering students: A brief overview in G (local) context. Journal of the Institute of Engineering, 11(1), 182-188.

Starcher, K., \& Proffitt, D. (2011). Encouraging Students to Read: What Professors Are (and Aren't) Doing About It. International Journal of Teaching and Learning in Higher Education, 23(3), 396-407

Stevens, R. A., Butler, F. A., \& Castellon-Wellington, M. (2000). Academic language and content assessment: Measuring the progress of English language learners. National Center for Research on Evaluation, Standards, and student testing. University of California, Los Angeles.

Thanky, P. (2014). Importance of English and communication skills for technical professionals. International Journal of Scientific Research, 3(4), 2011-2012

Wille, J. R. (2006). Measuring the Academic Achievement and English language Proficiency of Students at Secondary level.

Wongtrirat, R. (2010). English language proficiency and academic achievement of international students: A meta-analysis (Doctoral dissertation). Retrieved from ProQuest Dissertations and Theses database. (UMI No. 1434728.)

Zangani, E. \& Maleki, A. (2007). A Survey on the Relationship between English Language Proficiency and the Academic Achievement of Iranian EFL Students. Asian EFL Journal, 9(1), 86-96. 